\section{PSYCHIATRIC ASPECTS OF DIABETES} MELLITUS

DeAR Sir,

How disappointing that in Dr Wilkinson's otherwise excellent review article (Journal, January 1981, 138, 1-9) on diabetes mellitus he should ignore the interactional perspective. Whilst rightly stating that no studies have been designed to test the hypothesis that psychiatric factors play a direct part in the causation of diabetes mellitus, he neglects to mention the important studies of Minuchin and his colleagues in Philadelphia into factors that might contribute to the instability of the diabetes in certain children.

Using the serum level of free fatty acid (a precursor of ketosis as well as an indicator of emotional arousal), Minuchin et al (1978) studied the effect of parental conflict on diabetic children. They noted that in families of labile diabetic children, parental conflict was detoured via the diabetic child. Further, at the time one parent brought a child into the conflict the parent's free fatty acid level dropped to normal whilst the child's level rose, and failed to return to normal during the recovery period. The parents of stable diabetic children did not detour conflict via the child. Hence, the emotional arousal related to parental conflict in the labile diabetic children produced a significant physiological change, demonstrating a clear parallel between family interaction and physiological events.

When considering relevant psychological factors in any condition, attention should always be paid to family interaction as well as to the more traditional individual phenomenology and epidemiology.

BRYAN LASK

\section{Reference}

Minuchin, S., Rosman, B. \& Baker, L. (1978) Psychosomatic Families. London: Harvard Press.

\section{DeAR Sir,}

There are few critical studies of the interaction between diabetic children, their families, and the presentation or control of diabetes mellitus. Hence beliefs about an 'interactional perspective' tend to be in the nature of speculation. Minuchin and his colleagues' (1978) book Psychosomatic Families is concerned mainly with the 'systems model' of analysis in anorexia nervosa, the small part of the text which deals with physiological and psychological aspects of diabetes is both naive and tendentious. The authors' experimental design fails to conform to the principles of scientific method and their observations are presented in a form which prohibits scrutiny. Such research is likely to have low reliability and validity. Moreover Hinkle and Wolf (1952) give a more detailed account of the story.
A recent British investigation into emotional, behavioural, and educational disorders in diabetic children provides more robust information. With co-operation from parents and teachers, Gath, Smith and Baum (1980) collected interview, questionnaire, and behavioural scale data on 76 diabetic children (43 male, 33 female; mean age 10.9 years; mean duration of diabetes 3.5 years). In addition they looked for correlations between their findings and a paediatricians' estimates of the childrens' diabetic control over the period of one year (good/average/ poor). The results showed that although psychiatric disorder was not commoner in the diabetics than in classmate control subjects, as a group the diabetics were more backward at reading than their peers. Also, poor diabetic control was associated with the presence of psychiatric disorder, backwardness at reading, and (with statistical significance) adverse psychosocial factors as classified according to axis $\mathrm{V}$ of the multiaxial classification in ICD-9. So I agree with Dr Lask that the formulation of a clinical problem takes into account physical, psychological, and social variables.

Department of Psychological Medicine, GREG WILKINSON

King's College Hospital, London SE5 9RS

\section{References}

Gath, A., Smith, M. A. \& Baum, J. D. (1980) Emotional, behavioural, and educational disorders in diabetic children. Archives of Disease in Childhood, 55, 371-5.

Hinkle, L. E. \& Wolf, S. (1952) A summary of experimental evidence relating life stress to diabetes mellitus. Journal of the Mount Sinai Hospital, 19, 537-70.

Minuchin, S., Rosman, B. L. \& BAKer, L. (1978) Psychosomatic Families. Anorexia Nervosa in Context. London: Harvard University Press.

\section{CAUSAL MODELS AND LOGICAL INTERFERENCE IN EPIDEMIOLOGICAL PSYCHIATRY}

DEAR SIR,

I thank all the authors in the recent Discussion (Journal, December 1980, 137, 84-85) for their interest in my paper (Journal, April 1980, 136, 317-25).

I agree with Harré that a causal hypothesis must be derived from an underlying theory and I should have made this clear. Indeed Brown and Harris (1978) have suggested a speculative mechanism for a vulnerability hypothesis. It does seem however, that in the current state of knowledge the fact that a prima facie case cannot be made must undermine the underlying causal hypothesis. Post hoc salvage remains a dubious exercise.

Turning to Tennant and Thompson, the distinction between logical and material implication is exactly the one I was trying to make, although I did not express it 